\title{
DETECÇÃO DE SALMONELLA ALBANY, STAPHYLOCOCCUS COAGULASE POSITIVOS E MICRO-ORGANISMOS MESÓFILOS EM CARCAÇAS DE FRANGO IN NATURA
}

\author{
D.A.P. Brito, L.M.C. Alves, F.N. Costa
}

Universidade Estadual do Maranhão, Centro de Ciências Agrárias, Departamento de Patologia, Laboratório de Microbiologia de Alimentos, CP 9, CEP 65055-970, São Luis, MA, Brasil. Email: franeidec@yahoo.com.br

\section{RESUMO}

\begin{abstract}
Com o objetivo de avaliar as condições higiênico-sanitárias das carcaças de frango in natura comercializadas em mercados públicos do Município de São Luís, MA, foram colhidas quarenta amostras de carcaças de frango e analisadas quanto à pesquisa de Salmonella spp., Staphylococcus coagulase positivos e contagem padrão de micro-organismos mesófilos pelos métodos convencionais. Do total de amostras analisadas, 18 (45\%) apresentaram contaminação por Staphylococcus coagulase positivos, 5 (12,5\%) estavam contaminadas por Salmonella spp., identificadas como Salmonella Albany. A contagem padrão de micro-organismos mesófilos variou de $10^{3}$ a $10^{7} \mathrm{UFC} / \mathrm{g}$ no alimento analisado. Os resultados obtidos indicam que as condições higiênico-sanitárias das carcaças de frango in natura analisadas são insatisfatórias e que este produto pode ser um importante veículo de toxi-infecção alimentar.
\end{abstract}

PALAVRAS-CHAVE: Carcaça de frango, Salmonella Albany, Staphylococcus, mesófilos.

\section{ABSTRACT}

DECTECCION OF SALMONELLA ALBANY, COAGULASE POSITIVE STAPHYLOCOCCUS E MESOPHILIC MICRORGANISMS IN CARCASSES CHICKEN IN NATURA. The objective of this study was to evaluate the hygienic-sanitary conditions of in natura broiler carcasses commercialized in the market from São Luiz City, MA. Forty samples were collected and analyzed to research of Salmonella spp., coagulase positive Staphylococcus and of mesophilic microorganisms count. Among the analyzed samples, eighteen (45\%) were contaminated with coagulase positive Staphylococcus, five $(12,5 \%)$ were contaminated with Salmonella sp, being identified Salmonella Albany and counting of $10^{3}$ to $10^{7} \mathrm{UFC} / \mathrm{g}$ of mesophilic microorganisms. The results showed the hygienic-sanitary conditions samples analyzed were unsatisfactory and the consumption of this products can lead to an intoxication.

KEY WORDS: Broiler carcass, Salmonella Albany, Staphylococcus, mesophilic microorganisms.

O Brasil ocupa posição de destaque entre os maiores produtores mundiais de carne de aves. O consumo mundial da carne de frango tem aumentado substancialmente nas últimas décadas e, paralelamente, tem se preocupado com a qualidade deste produto, especialmente pelas implicações como veículo de toxi-infecções alimentares (VIEIRA, 2000).

A contaminação biológica de carcaças de frango ocorre em todas as operações de abate, armazenamento e distribuição e, normalmente, conforme o manejo sanitário durante a criação, as próprias aves abatidas podem ser fonte inicial de contaminação (LEITão, 2002). A incidência e quantidade dos micro-organismos oriundos dessas contaminações irão determinar o tempo de prateleira, assim como a qualidade sanitária das carcaças de frango (SILVA; GANDRA, 2004).
A Salmonella spp. está entre os patógenos mais relevantes nas contaminações e em surtos associados à carne de frango. A importância de sua disseminação vem sendo amplamente estudada na cadeia produtiva das aves, com positividade bastante variável em carcaças de frango (NogueIra et al., 2005). O gênero Salmonella é composto por diferentes sorovares, podendo acarretar tanto a salmonelose aviária quanto a humana, quando da ingestão de produtos avícolas contaminados (ANDREATTI FilHo et al., 2001).

Vários municípios brasileiros sofrem com as falhas nos sistemas de inspeção e de fiscalização de produtos deorigemanimal. Nocasodacarnedefrango,écomum oabateclandestinoemfeirasemercados públicos, onde condições higiênico-sanitárias são inadequadas e o produto é frequentemente comercializado em pontos devenda sem refrigeração, expondoos consumidores a inúmerasenfermidades (LoGUERCioetal.,2002). Assim, 
este estudo objetivou avaliar a qualidade sanitária das carcaças de frango in natura comercializadas de mercados públicos de São Luís, MA.

Foram colhidas no início da manhã, aleatoriamente, 40 carcaças de frangos comercializadas sob temperatura ambiente, proveniente de quatro mercados públicos do Município de São Luís, MA, onde se realizava o abate artesanal de frangos. As amostras, já embaladas em sacos plásticos, foram acondicionadas em caixas de isopor com gelo reciclável e transportadas para o Laboratório de Microbiologia de Alimentos da Universidade Estadual do Maranhão.

No laboratório, as amostras foram pesadas e então retiradas das suas embalagens originais, após desinfecção destas com álcool a 70\%, e colocadas dentro de saco plástico esterilizado. Foram transferidos $300 \mathrm{~mL}$ de água peptonada a $0,1 \% \mathrm{e}$ realizado o processo de enxaguadura, segundo a metodologia de Cox et al. (1978). A solução obtida foi transferida, asseptica-mente, para um frasco de vidro estéril e, a partir desta, foram realizadas a pesquisa de Staphylococcus coagulase positivos, contagem padrão de micro-organismos aeróbios mesófilos e Salmonella spp., segundo metodologias descritas pela ABNT (1991), ICMSF (1988) e ICMSF (1978), respectivamente. Em caso de confirmação do gênero Salmonella, as cepas foram inoculadas em ágar nutriente, incubadas à $37^{\circ} \mathrm{C}$, por 24 horas e enviadas para o Instituto Adolfo Lutz, em São Paulo, para realização da sorotipificação.

Verificou-se que do total de 40 amostras de carcaça de frango in natura, 5 (12,50\%) apresentavam-se contaminadas por Salmonella spp. (Tabela 1). Este resultado é inferior aos obtidos por outros pesquisadores como ReZENDE et al. (2005), Silva et al. (2004) e Almeida FilHo et al. (2003), que verificaram, respectivamente, a frequência de 19,8\%, 43\%, 50\% de carcaças de frango in natura provenientes de abatedouros, feiras e estabelecimentos comerciais no Brasil. Porém, superior a 2,5\% de contaminação encontrado por TESSARI et al. (2008) em carcaça de frango industrialmente processada. No contexto da epidemiologia da Salmonella spp., a presença dessa bactéria nas carcaças de frango revela a existência de aves portadoras nas criações avícolas, deficiência das condições higiênico-sanitários nas operações de abate nas feiras livres, instalações inadequadas e a possível presença de manipuladores das carcaças de frango como portador e veiculador de salmonelas para os alimentos (GIL, 2000; SALLES et al., 2002).

A Salmonella Albany foi o único sorotipo isolado nas cinco amostras contaminadas por salmonela. Este sorovar não é encontrado com frequência causando infecção em seres humanos ou em animais, porém, tem sido isolado de carcaças de frango (D'Aoust, 1997). VAdHNANASIn etal. (2004) e FuZIHARAet al. (2000) verificaram a frequência de $S$. Albany de 33,3\% e12\%, respectivamente, em isolamentos de salmonelas em carcaças de frango. No Brasil, relato de isolamento desse sorovar foi descrito por LuIz et al. (2004) em carne de aves mecanicamente separada, usada para produção de salsichas no Estado deSão Paulo. Emum estudo molecular de $S$. Albany isoladas de alimentos, Doublet et al. (2003) descrevem a presença de genes que conferem resistência múltipla a antibióticos nas cepas de salmonelas analisadas. De acordo com os autores, tal resistência pode dificultar o tratamento de infecções intestinais provocadas pela $S$. Alvany, agravando quadros clínicos curáveis (SENA, 2000).

Em virtude da complexidade dos processos de controle de Salmonella spp. na produção da carne de frango, a legislação brasileira não inclui a Salmonella como padrãomicrobiológico de qualidadeem carcaça defrango. A Agência Nacional de Vigilância Sanitária (ANVISA) considera que "a presença desse patógeno nas carcaças de frango existe de forma crítica e é um problema mundial, não existindo medidas efetivas de controle que possam eliminá-la da carne crua", ficando na responsabilidade do consumidor adotar as boas práticas de manipulação, conservação e preparo do alimento (BrasiL, 2000). Assim, as carcaças de frango que são consumidas sem tratamento térmico eficiente e/ou sem cuidados de manipulação no preparo podem ser fontes potenciais de Salmonella para os consumidores.

Constatou-se ainda que todas (100\%) as 40 amostras decarcaças defrango in natura analisadas estavam contaminadas por Staphylococcus spp., com contagem máxima de $10^{7} \mathrm{UFC} / \mathrm{g}$ de carne de frango analisada. Essa elevada população de Staphylococcus spp., verificada neste trabalho, foi superior ao encontrado por FREITAS et al. (2001), que observaram contagem máxima de $10^{4} \mathrm{UFC} / \mathrm{g}$ em carcaça de frango in natura, obtidas de abate artesanal sem inspeção sanitária.

Por serembactériasqueseencontram, naturalmente, na pele e anexos das aves e do ser humano, a alta contagem de estafilococos deveu-se tanto a falhas na higiene e no processo de abate como pela excessiva manipulação que sofrem as carcaças de frango nos locais de abate em mercados públicos (AzEvEDo et al., 2005). A falta de refrigeração das carcaças de frango por longos períodos, nesses locais, tambémjustifica as elevadas contagens de Staphylococcus spp., visto quea temperatura ambiente gera condições ótimas para o desenvolvimento dessas bactérias e para maioria das bactérias patogênicas (Pereira et al., 1999).

Ainda em relação aos Staphylococcus spp., verificou-se que 18 (45\%) das 40 carcaça analisadas estavam contaminadas por Staphylococcus coagulase positivos (Tabela 1). Tal resultado pode significar risco para os consumidores, visto que algumas espécies deste grupo, como S. aureus, podem ser capazes de produzir enterotoxinas causadoras de várias intoxicações alimentares (NovAK, 1999; SILVA; GANDRA, 2004). 
Tabela 1 - Pesquisa de Staphylococcus coagulase positivos, contagem padrão de micro-organismos aeróbios mesófilos e pesquisa de Salmonella spp. em carcaças de frango in natura comercializadas em mercados públicos do Município de São Luís, MA.

\begin{tabular}{|c|c|c|c|c|c|c|c|}
\hline \multirow[t]{2}{*}{$\begin{array}{l}\text { Mercado } \\
\text { público }\end{array}$} & \multirow[t]{2}{*}{$\begin{array}{c}\text { № de } \\
\text { amostras }\end{array}$} & \multicolumn{2}{|c|}{$\begin{array}{c}\text { Amostras contaminadas } \\
\text { por Salmonella }\end{array}$} & \multirow{2}{*}{$\begin{array}{l}\text { População de } \\
\text { Staphylococcus } \\
\text { spp. (UFC/g*) }\end{array}$} & \multicolumn{2}{|c|}{$\begin{array}{l}\text { Amostras contaminadas } \\
\text { por } S \text {. coagulase Positivos }\end{array}$} & \multirow{2}{*}{$\begin{array}{c}\text { População de } \\
\text { bactérias } \\
\text { mesófilas (UFC/g*) }\end{array}$} \\
\hline & & $\mathrm{N}^{\circ}$ & $\%$ & & $\mathrm{~N}^{\circ}$ & $\%$ & \\
\hline A & 10 & 1 & 10,00 & $10^{3}$ a $10^{5}$ & 5 & 50,00 & $10^{3}$ a $10^{6}$ \\
\hline B & 11 & 2 & 18,18 & $10^{3}$ a $10^{5}$ & 6 & 54,50 & $10^{4}$ a $10^{6}$ \\
\hline $\mathrm{C}$ & 10 & 2 & 20,00 & $10^{4}$ a $10^{7}$ & 2 & 20,00 & $10^{4}$ a $10^{7}$ \\
\hline $\mathrm{D}$ & 9 & 0 & 00,00 & $10^{4}$ a $10^{5}$ & 5 & 55,50 & $10^{4}$ a $10^{6}$ \\
\hline Total & 40 & 5 & 12,50 & & 18 & 45,00 & \\
\hline
\end{tabular}

*unidades formadoras de colônias por grama.

Em relação aos micro-organismos aeróbios mesófilos, as contagens nas amostras analisadas apresentaram uma variação de $10^{3}$ a $10^{7} \mathrm{UFC} / \mathrm{g}$ de carne de frango (Tabela 1). Apesar de não existir um padrão para os micro-organismos aeróbios mesófilos em carcaças de frango, os resultados evidenciam excessiva contaminação do alimento analisado, com "vida de prateleira" reduzida (SILVA et al., 2001). Tais resultados reforçam a deficientes práticas de limpeza e desinfecção da superfície de contato com as carcaças de frango e a conservação do produto em temperatura incorreta.

Nas condições em que a pesquisa foi realizada e de acordo com os resultados obtidos, foi possível concluir que as carcaças de frango in natura de mercados públicos de São Luís, MA, possuem condições higiênicas insatisfatórias e podem ser responsáveis por toxi-infecção alimentar por Salmonella spp. e intoxicações causadas por estafilococos coagulase positivos.

\section{REFERÊNCIAS}

ALMEIDA FILHO, E.S.; SIGARINI, C.O.; BORGES, N.F.; DELMONDES, E.C.; OZAKI, A.S.; SOUZA, L.C. Pesquisa de Salmonella sp em carcaças de frango (Gallus gallus) comercializadas em feira livre ou em supermercado no município de Cuiabá, MT, Brasil. Higiene Alimentar, v.17, n.110, p.74-79, 2003.

ANDREATTI FILHO, R.L.; FERNANDES, S.A.; BORETTI, L.P.; BARROS, M.R.; DEL BEM, S.R.; FONTANA, A.; SAMPAIO, H.M.; SAVANO, E.N. Sorovares de Salmonella isolados de materiais avícolas no período de 1994 a 1999. Revista de Educação Continuada do CRMV - SP, v.4, n.3, p.90-101, 2001.

ASSOCIAÇÃO BRASILEIRA DE NORMAS TÉCNICAS. MB3464: Contagem de Staphylococcus aureus em placas. Rio de Janeiro: ABNT, 1991.
AZEVEDO, A.P.; VERRI, M.P.; AZEVEDO R.V.P. Resistograma e fenotipagem de Staphylococcus aureus, isolados de manipuladores de alimentos. Higiene Alimentar, v.19, n.128, p.133-143, 2005.

BRASIL. Agência Nacional de Vigilância Sanitária. Consulta Pública - CP, n 49, de 13 de julho de 2000. Regulamento técnico para instruções de uso, preparo e conservação na rotulagem de carnes e miúdos de aves crus, resfriados ou congelados. Diário Oficial. Brasília. 17 de julho de 2000, n¹36-E, Seção 1.

COX, N.A; MERCURI, A.J.; TANNER, D.A.; CARSON, M.O.; THOMSON, J.E.; BAILEY, M.S. Effectiveness of sampling methods for Salmonella detection on processed broilers. Journal of Food Protection, v.41, p.341-343, 1978.

D’AOUST, J.Y. Salmonella species. Food microbiology fundaments and frontiers. Washington: ASM, 1997. p.129158.

DOUBLET, B.; LAILLER, R.; MEUNIER, D.; BRISABOIS, A.; BOYD, D.; MULVEY, M.R.; CHASLUS-DANCIA, E.; CLOECKAERT, A. Variant Salmonella genomic island 1 antibiotic resistence gene cluster in Salmonella enterica serovar Albany. Emerging Infectious Diseases, v.9, n.5, p.585-591, 2003.

FREITAS, M.F.L.; MOTA, R.A.; VILELA, S.M.O; SENA, M.J.; BEZERRA, R. Cepas de Staphylococcus sp. isoladas de carcaças de frango comercializadas na cidade do Recife - PE, Brasil. Ciência Animal Brasileira, v.2, n.2, p.139-145, 2001.

FUZIHARA T.O.; FERNANDES, S.A.; FRANCO, B.D. Prevalence and dissemination of Salmonella serotypes along the slaughtering process in Brazilian small poultry slaughterhouses. Journal of Food Protection, v.63, n.12, p.1749-53, 2000.

GIL, I.J.A.S. Manual de inspeção sanitária de carnes. 2.ed. Lisboa: Fundação Calouste Gulbenkian, 2000. 485p. 
INTERNACIONAL COMMISSION ON MICROBIOLOGICAL SPECIFICATION FOR FOOD. ICMSF. Microrganisms in food. I- Their significance and methods of enumeration. 2.ed. Toronto: University of Toronto Press, 1978, 434p.

INTERNACIONAL COMMISSION ON MICROBIOLOGICAL SPECIFICATION FOR FOOD. ICMSF. Microrganisms in food. I- Their significance and methods of enumeration. 2.ed. Toronto: University of Toronto Press, 1988. 436p.

LEITÃO, M.F.F. Qualidade e segurança alimentar em produtos avícolas. In: CONFERÊNCIA APINCO DE CIÊNCIA E TECNOLOGIA AVÍCOLAS, 2002, Campinas, SP, Resumos. Campinas: FACTA-Fundação Apinco de Ciência e Tecnologia Avícolas, 2002. p.215-232.

LOGUERCIO, A.P.; SILVA, W.P., ALEIXO, J.A.G. Condições higiênico-sanitárias no processamento de carne bovina moída. Higiene Alimentar, v.16, n.98, p.63-66, 2002.

LUIZ, A.F.; MOREIRA, F.C.; CORREA, E.F.; FALCÃO, D.P. Monitoring of the dissemination of Salmonella in the chicken Frankfurt-sausage production line of a sausage factory in the State of São Paulo, Brazil. Memórias do Institito Oswaldo Cruz, v.99, n.5, p.477-480, 2004.

NOGUEIRA, N.A.P.; VERDE, J.C.L.; BASTOS, G.M.; BRITO, E.C.de O.; OLIVEIRA, M.T. de; SOARES, M.I.M.; AGUIAR, A.C.L. Bactérias do gênero Salmonella em carcaças de frango comercializadas em Fortaleza, CE. Higiene Alimentar, v.19, n.137, p.87-89, 2005.

NOVAK, F.R. Ocorrência de Staphylococcus aureus à meticilina em leite humano ordenhado. 1999. Tese (Doutorado em Microbiologia) - Instituto de Microbiologia Prof. Paulo de Góes, Universidade Federal do Rio de Janeiro, Rio de Janeiro, 1999.

PEREIRA, M.L.; PEREIRA, J.L.; SERRANO, A.M. Estafilococos e Alimentos: possibilidades de disseminação através do portador humano e animal. Higiene Alimentar, v.13, n.66/67, p.48-55, 1999.

REZENDE, C.S.M.; MESQUITA, A.J. de; ANDRADE, M.A.; LINHARES, G.F.C.; MESQUITA, A.Q.; MINAFRA, C.S. Sorovares de Salmonella isolados de carcaças de frangos de corte abatidos no Estado de Goiás, Brasil, e perfl de resistência a antimicrobianos. Revista Portuguesa de Ciências Veterinárias, v.100, n.555-556, p.199203, 2005.

SALLES, M.A.; SILVA, P.K.S.; FONSECA, V.R.S.; CARNEIRO, A.L.; BRANCO, F.R.; SILVA, P.L.; ALVES, N.F.; CUNHA, A.P. Pesquisa de Salmonella sp através de provas de triagem rápida e convencional, em carcaças de frangos abatidos no município de Uberlândia, MG. Higiene Alimentar, v.16, n.92/93, p.36-40, 2002.

SENA, M.J. Perfil epidemiológico, resistência a antibióticos e aos conservantes nisina e sistema lactoperoxidase de Staphylococcus sp. isolado de queijos coalho comercializados em Recife/PE. 2000. 75f. Dissertação (Mestrado em Medicina Veterinária) - Escola de Veterinária, Universidade Federal de Minas Gerais, Belo Horizonte, 2000.

SILVA, M.C.D.; RAMALHO, L.S.; FIGUEREDO, E.T. Salmonella sp em ovos e carcaças de frango "in natura" comercializadas em Maceió, AL. Revista Higiene Alimentar, v.18, n.121, p.80-84, 2004.

SILVA, W.P.; GANDRA E.A. Estafilococos coagulase positiva: patógenos de importância em alimentos. Higiene Alimentar, v.18, n.122, p.32-40, 2004.

SILVA, N.; JUNQUEIRA, V.C.A.; SILVEIRA, N.F.A. Manual de métodos de análise microbiológica de alimentos. 2.ed. São Paulo: Varela, 2001.

TESSARI, E.N.C.; CARDOSO, A.L.S.P.; KANASHIRO, A.M.I.; STOPPA, G.F.Z.; LUCIANO, R.L.; CASTRO, A.G.M. de Ocorrência de Salmonella spp. em carcaças de frangos industrialmente processadas, procedentes de explorações industriais do Estado de São Paulo, Brasil. Ciência Rural, v.38, n.9, p.2557-2560, 2008.

VADHANANSIN, S.; BANGTRAKULNONTH, A.; CHIDKRAU, T. Critical control points for monitoring salmonellae reduction in Thai commercial frozen processing. Journal of Food Protection, v.67, n.7, 2004.

VIEIRA, S.L. Considerações sobre as características de qualidade de carne de frango e fatores que podem afetá-la. Arquivos do Instituto Biológico, São Paulo, v.67, n.1, p.8-16, 2000.

Recebido em 20/7/08

Aceito em 18/3/10 